\title{
Intraoperative Head and Neck Injury
}

National Cancer Institute

\section{Source}

National Cancer Institute. Intraoperative Head and Neck Injury. NCI Thesaurus. Code C78381.

Damage to head and neck during a surgical procedure. 